\title{
INNOVATION AND COMMUNICATION TECHNOLOGIES + PROBLEM BASED LEARNING: A NEW APPROACH FOR TEACHING ARCHITECTURE
}

\author{
Ruiz-Jaramillo, J. $^{1}$, Alba-Dorado, M.I. ${ }^{1}$, Cimadomo, ${ }^{1}{ }^{1}$, Jiménez-Morales, E. ${ }^{1}$, \\ Joyanes-Díaz, M.D. ${ }^{1}$ \\ ${ }^{1}$ Art and Architecture Department. University of Malaga (SPAIN)
}

\begin{abstract}
This article presents the results obtained during its first year of application in the educational innovation project called "New frameworks of teaching: ICT applied to problem based learning in technical bachelors" (PIE 15-166) developed at the School of Architecture in the University of Malaga. This has been focused on the development of educational strategies based on exploiting the potential of ICT, taking as a framework the ABP. Its application on subjects from different areas of knowledge (architectural composition, urban planning, projects and architectural constructions) has allowed assessing the adaptability of this methodology depending on the content. Among the obtained results can be highlighted the improvement in cross curricular coordination between subjects from different fields of studies, providing different ways of synchronous and asynchronous communication between students and teachers to generate a greater interaction between all the involved subjects; increasing in addition the interest and an improvement of the results.
\end{abstract}

Keywords: TIC tools, teaching, architecture, ABP, cross-coordination

\section{INTRODUCTION}

Despite its presence in the University educational environment, new technologies integrated in teaching has not produced key improvements both in teaching quality and the acquisition of knowledge by students. Teaching continues anchored in one-way transmission of content, making students mere passive recipients of information and generating limited expectations with respect to the utility and application of this theoretical content to real-world practical scenarios.

Progressive changes made to the curricula at schools of architecture in Spain have led to redistribution and update contents but having minor impact on the way in which they are transmitted. Learning on different subjects are linked to the masterclass supported by resolution of theoretical exercises focussed most of time over unrealistic models with limited application to the reality of the profession. In this way, the adaptation to the EHEA of these new curriculums has led to create an opportunity of introducing improvements on university teaching, solving those existing difficulties, especially the habit of consider the individual study before the exam enough to pass the subject. This goes together with the limited training oriented towards the reflection and critical necessary to create an individual thinking, generating with difficulty a fluent interrelation and discussion between professor and students [1].

\section{GENERAL FRAMEWORK}

\subsection{Backgroung}

During the course 2012-2013, in the subject "Structures II" on the bachelor in architecture at the University of Malaga was introduced one methodological variation. The traditional presentation with slides were reinforced and supported by online activities developed using the tools available in the virtual campus of the University of Malaga. The students have to solve individually and weekly these online exercises. Additionally, the resolution of these activities was included in the evaluation of the course as part of the final mark. According to a survey made to the students, it was possible to appreciate objectively a remarkable increase of the interest for the subject as well as an increase of the success rate [2].

Based on the conclusions obtained during the application of this methodological innovation, it is generated an environment focussed on the enrichment of the teaching and learning process based on 
the application of problem based learning ( $\mathrm{PBL}$ ) supported by the use of new information and communication technologies (ICTs). This methodology involves the use of technological tools in order to enrich the educational process as well as the evaluation system, offering to the students an experience close to reality. In addition, the familiarity of students with new technologies, learning tools based on them generates an attractive and stimulating teaching experience, increasing the motivation and as a result of this encouraging the self-learning at the same time.

Analysing the application of the PBL to the university teaching, specifically to the Bachelor of Architecture, it is possible to emphasize the experiences performed at the universities of Delf (Holland) or Newcastle (Australia) [3]. In particular, the curriculum of the last one mentioned in 1985 was completely structured around a central problem per semester and therefore the teaching of all subjects during the semester was centred on it. This was designed to make possible the involvement of all areas of knowledge in the teaching, promoting the cross-coordination between them. From this experienced it was possible to conclude that one of the main difficulties of the application of this system came from the interaction of specific subjects with this multidisciplinary approach.

\subsection{Educational Innovation Project}

From the described background, a set of teachers of the School of Architecture of the University of Malaga proposed the development of an educational innovation project (EIP) called "New frameworks of teaching: ICT applied to problem based learning in technical bachelors" (PIE 15-166). The main objective of the project is to apply a teaching methodology based on PBL developed as in the classroom as out of them through the application different ICT tools provided mainly by the virtual campus of the University of Malaga, making easier the development of activities based on real cases supported by the theory given in class.

This two years long project was applied initially during the course 2015-2016. The subjects included are specified in table 1:

Table 1. List of subjects, courses and ECTS

\begin{tabular}{cccc}
\hline Subject & Course & $\begin{array}{c}\text { Area of } \\
\text { Knowledge }\end{array}$ & ECTS \\
\hline Workshop I-B & $1^{\text {st }}$ & $\begin{array}{c}\text { Architectural } \\
\text { Projects }\end{array}$ & 6 \\
$\begin{array}{c}\text { History of Art and } \\
\text { Architecture I }\end{array}$ & $2^{\text {nd }}$ & $\begin{array}{c}\text { Architectural } \\
\text { Composition }\end{array}$ & 6 \\
$\begin{array}{c}\text { History of Art and } \\
\text { Architecture II }\end{array}$ & $3^{\text {rd }}$ & $\begin{array}{c}\text { Architectural } \\
\text { Composition }\end{array}$ & 6 \\
Urban Planning IV & $4^{\text {th }}$ & $\begin{array}{c}\text { Urban and Regional } \\
\text { Planning }\end{array}$ & 6 \\
Building Structures IV & $4^{\text {th }}$ & $\begin{array}{c}\text { Architectural } \\
\text { Constructions }\end{array}$ & 6 \\
\hline
\end{tabular}

Following are detailed the main specific objectives to be achieved by the application of the project:

1. Contributing to professional development of students through a closer linkage between competence - learning. This imply a development of the connection between the academic experience and training being the students capable to address in the future real problems related to the specific professional activity.

2. Introducing a continuous evaluation process based on the application of ICT, receiving the student in each phase of the work information about their progress (feedback both for students and teachers) and additionally generating a better agility of the evaluation process.

3. Generating learning based on dynamic methodologies to encourage critical and analytical thinking, fomenting the acquisition of skills to create personal criteria. This allow the student to face complex real problems that involve cross curricular connections between subjects. 
4. Improvement of the pass rates in the involved subjects through the motivation of the student, increasing its interest in theoretical aspects as well as the attendance rate to the class.

\section{METHODOLOGY AND RESULTS: APPLICATION TO DIFFERENT FIELDS OF STUDIES}

From the general framework proposed by the EIP approach, for each of the subjects involved it is designed previously at the beginning of the course a strategy based on the proposal to the students to develop a project as part of the evaluation. This have to be performed during the semester. To monitor the work are used both classes and the tools provided by the ICT included in the virtual campus. The following paragraphs summarize the application of these general guidelines to the particularity of each of the subjects involved.

\subsection{Architectural Projects}

The application of ICT to the teaching in the Architectural Projects area allows expanding the short space of the classroom teaching using for this purpose a digital space. So in this case, ICTs constitute a teaching instrument of great interest in the process of teaching - learning of the architectural project. Specifically, the methodology is applied in the subject "Workshop I-B" during the first course which is the first contact with the process of architectural creation.

During its development, it is proposed the realization of various training activities oriented to encouraging a greater participation of the students in their own training with the aim that they begin to acquire a wealth of knowledge and an optimal training for their initiation into the process of projecting architecture. These activities are linked to the development of individual and / or group work of the students in the workshop, contemplating their projection to a virtual environment through e-Learning platform offered by the University of Malaga.

Thus, in order to implement all potential that new ICTs offer to expedite the development of the course, by increasing the interactivity in the teacher-student and student-student relations and contributing to collective learning, it is launched activities based on the use of the virtual platform, allow the discussion of certain aspects related to the subject and the work of the students. To this end, during the semester activities that encourage consultations or resolving specific questions of general interest through a forum for communication and discussion, are made; promote and facilitate teamwork through shared spaces by creating a virtual workshop; assessing and stimulating the learning in virtual environments by conducting surveys.

In addition external electronic tools are incorporated, thereby promoting work on the students' network and promoting channels of opinion and debate in the educational environment. In this case, the activity that proposal is entitled "The architect's digital notebook" and aims that students register through the creation of a blog, those experiences associated with their introduction to architectural project, drawn both inside and outside the classroom and referred to the field of culture. This is configured as a diary in which the student is registering the documentation handling concerning to the exercise that are developing, writing down ideas, arguments or thoughts reflecting the activities present in their training during this first year.

The blog promotes active participation by students, forming a space to present differently the work done. The fact that students show to the "open network" their work does that they pay more attention to the time to do it, thereby increasing the quality. It also allows them to develop a synthesis capacity to convey concepts and ideas through drawings, sketches and short texts. This activity allows the continuous monitoring of the work done by students and this can be consulted in real time and commented by both the teacher and the rest of his companions, favoring the necessary feedback at critical moments and providing the process of developing the project with the necessary dynamism, monitoring and care. The blog also contributes to collective learning in which each student reflects with their peers.

\subsection{Architectural composition}

\subsubsection{History of Art and Architecture I}

The objective pursued is to create a whole apprehensive look through a journey into the past as a means of re-discovery and interpretation of the codes along different periods and systems innervated. 
To achieve these goals it is required a different approach to the Theory of Architecture, as perception of facts which are able to interfere and impact in the process of thinking and living reality within each historical context, determined by social, economic, psychological and semiotic conditions [4].

Methodologically, the development of a historical matrix organized in horizontal and vertical susceptible inputs such depth and interpretation, as the student is able to confer arises. The guidelines for conducting structured in a horizontal inputs (extension) organized in different ancient civilizations, plus a vertical inputs (depth) where three main entrances are set, based on a condition of unavoidable contour that constitutes the natural environment itself, place or its transformation into landscape. In the horizontal entries are the different topics of the subject, from Pre-History to the Middle Ages, while the vertical inputs are developed in functional constructive or possibilities dimension, which represents matter (nature), the spatial dimension and, resulting from the application of rational thought (art) and art that reflects the spiritual dimension focused on the conception of nature that man sets in each time interval.

This huge elastic matrix is proposed as the problem to resolve, as learning resource for the development of the subject and its evaluation, being the essential material on which works the whole class together by finding graphic information and use ICT through the virtual campus. The tools used to the progressive development of this matrix along the course, generates the aims for analyze and discuss along the practical classes. Therefore, throughout theoretical teaching, the teacher can follow permanently the updated work by all the groups of students, creating a reference framework for each topic within the subject.

The tool used in the first phase is the "Database", whose operation and virtual dynamic is quite similar to the concept of development of the matrix information. It allows uploading information from different groups of students, both in the form of text files, pictures or videos. The teacher sets in advance an appropriate template to allow later management questions as a records repository. As a complement, the tool "Workshop" in virtual campus, where for a set time, the teacher can evaluated uploads content by each group, and can also compare the opinion of other users, who anonymous way, can evaluate the work of classmate. This way for work lets the teacher to direct the contents of the theoretical classes depending on how the research and information management develops, and in addition, it transforms a basically theoretical subject in an active and participatory goal.

Finally, as result of all the process, the global reading of the results, summarized in the great matrix, provide a new concept for study, the historic landscape, and its permanent updating. This concept, brought to the Theory of Architecture, mean a new learning objective, where Architecture has a relevant dimension to stimulate the students.

\subsubsection{History of Art and Architecture II ( $3^{\text {rd }}$ year)}

This course provides an analysis of the classical language and its evolution in the Modern Era as a tool to reflect on its meaning and use. The greatest weight is given to learning the verbal and symbolic dimension, related to the knowledge of the iconic buildings of the times studied not as a meaning in itself, but in order to understand the processes and relationships produced from the Renaissance to the Enlightenment. The incorporation of ICTs as tools to support the learning process is understood not as a mere passive act of listening and memorization, but as an active process that improves critical thinking, problem solving and collaboration capabilities [5]. The activities have focused on two main instruments that bring a revolution in the dynamics of a theoretical course, based on the EHEA framework: on one hand the implementation of Pinterest, a social network in which predominates the use of images on the written word; secondly the inclusion of an exercise based on PBL, requiring deeper attention to the subject for a correct development.

The main strategy proposed with the use of Pinterest seeks not only the active participation of students, but also to give them more control and decision-making power over the content of the subject. So are the students themselves who prepare and somehow define these contents, using this OSN as a teaching tool for collection and distribution, releasing it from other more social relational activities. The applied dynamic offers students a list of monuments to be searched online for relevant images. These images have to be uploaded to a Pinterest board shared by the entire group and the teacher, who uses them in the theoretical lectures. This collaborative task simultaneously induces a reflection on the weaknesses and strengths of architectural history contents on the network, and generates a Community of Practice, understood as an extension of knowledge through relationships between people with similar interests [6]. At the end of the course, each student has achieved a digital portfolio of images which can has been used as a template to take notes in class or to complete them 
taken in a traditional manner. The results, corroborated by an anonymous survey, confirm expectations: if on one hand the limited use of similar tools in the degree is recognized, also the improvements in learning arising from their use have been unanimously recognized [7].

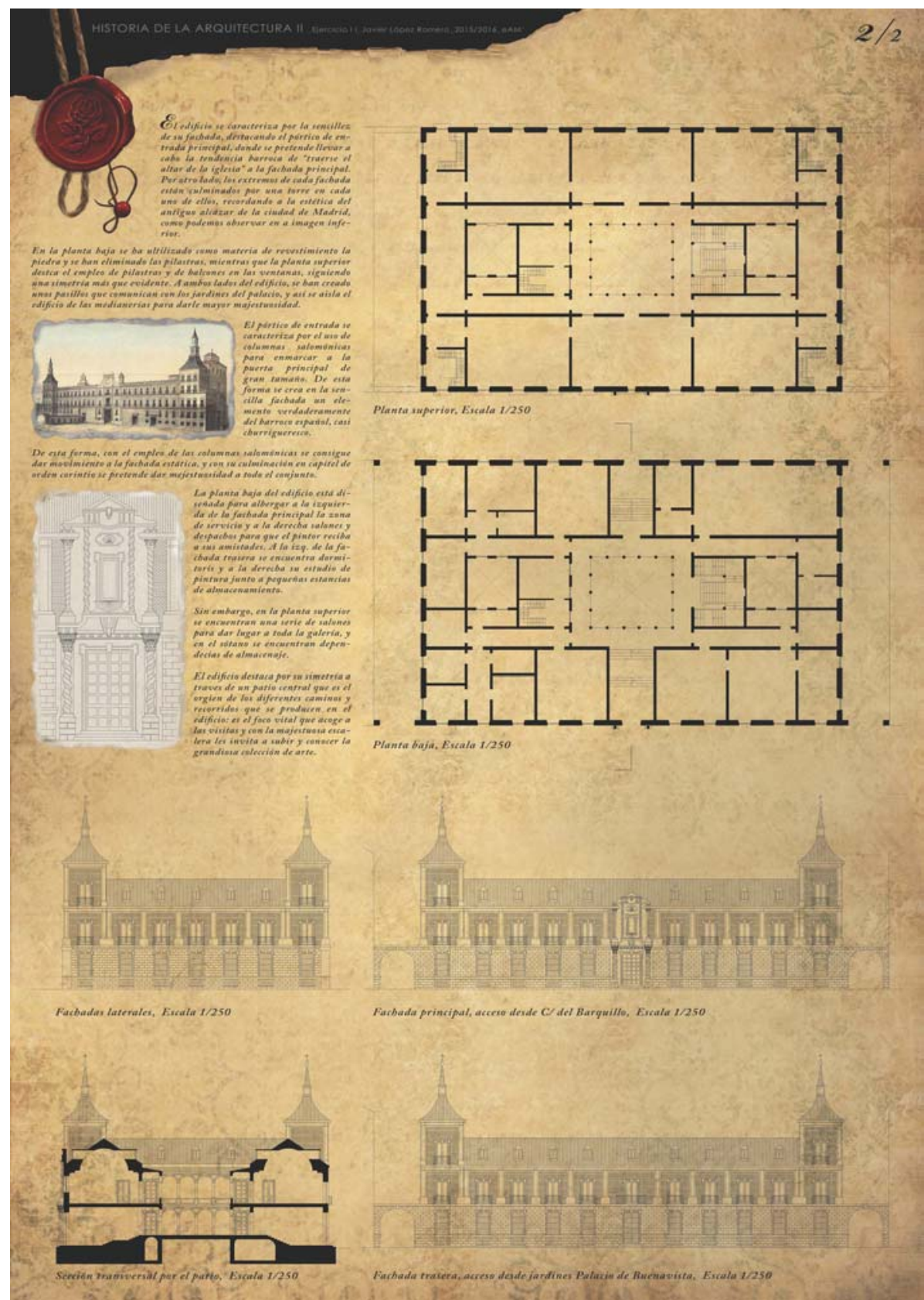

Fig. 1. Exercise developed during the academic year 2015/16: Small palace for Goya in Madrid (1794 ca.). Student: Javier López Romero

The second task required involved the realization of an architectural project (design studio project), settled in a time between the $5^{\text {th }}$ and the $18^{\text {th }}$ century. Students had to choose a place, a patron and therefore a specific time when acclimate the work, in addition to the typology of construction. Develop a project under these assumptions requires an indirect learning of the contents of the subject (traditionally theoretical), needed for a previous documentation on different aspects of building typology to design: constructive elements, compositional language, user needs related to the customs of the time. The student faces to the need to find solutions to its design, only accomplished through a deep analysis of the examples studied. This exercise has a dynamic effect on the subject and on the relationships between teachers and students which are common in Design Studios, but not so usual in theoretical courses (Fig. 1). 


\subsection{Architectural construction}

The application of the methodology to the area of Architectural Constructions takes place in the course "Structures IV." The aim of the course is the design and dimensioning of structures from the loads and stresses of the elements, focusing on learning the behavior of different materials (mainly steel and concrete) again these efforts, proceeding to its optimum dimensioning and obtaining the reinforcements when needed. This learning is based on the knowledge of the requirements set out by the different standards contained in the Spanish regulations on structural calculation.

To complement the theoretical lessons, students in groups of 3 members have to develop a project where are progressively applied the concepts explained during the class. Each team works as a small consulting that are requested to calculate the structure of the project selected from the set proposed by the teacher. The process begins therefore with the integration of the structure in the selected project, moving then to define the acting loads, obtaining load combinations and once achieved the stresses by using a simple computer application, proceed to dimension beams and columns for one of the main frames. Specifically, during the course 2015-2016 it was proposed the structural study of the Case Study Houses, selecting each group one of the models. The work was monitored partially during small group classes and during the tutorial hours and continuously from ICT tools for example the specific forums for each group.

In addition, in order to incorporate the not in person work of students into the usual dynamics, a series of virtual activities have been developed varying its design according to the content that is intended to evaluate. In this way, it have been designed interactive presentations (SCORM) as well as assessment questionnaires based on practical exercises or questionnaires based on theory (Fig. 2).

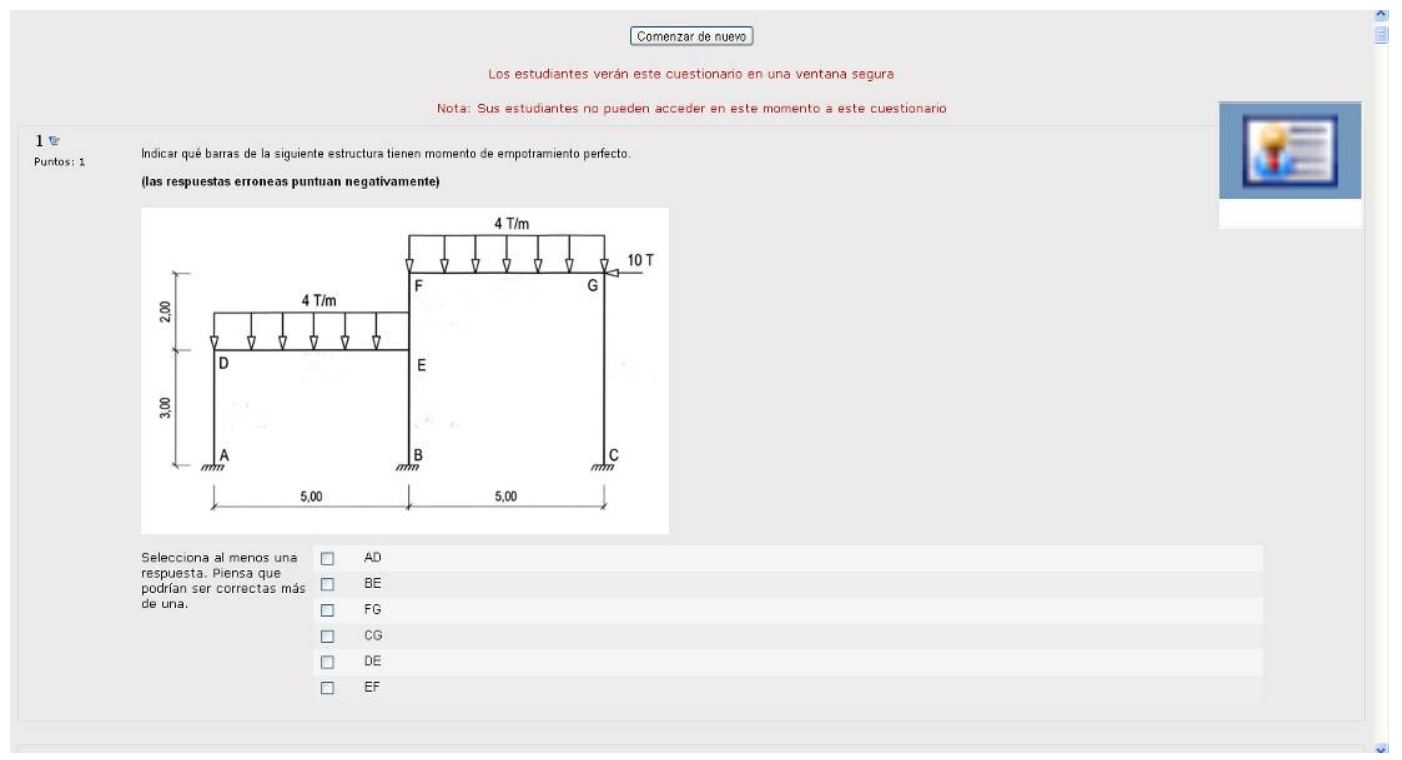

Fig. 2. Example of time limited practical questionnaire included in the virtual campus of the subject "Building Structures IV"

\subsection{Urban planning}

Urban Planning has usually analysed the territory using many different cartographic data. Nowadays, in an increasing digitalizing world, it is essential to give students the opportunity to access and process cartographic-based information. Therefore, the ICT was implemented in our Urban Planning subject and it produced a significant teaching experience. The digital databases were incorporated into the classroom in order to go further in analysing the territory and the ICT allowed students to innovate, mainly in Urban Planning approaches. Furthermore, one of the most important goals of this exercise was to obtain the active participation of the teaching community and create virtual methodologies based on a collective knowledge.

A "professional imitation" methodology was used to achieve these aims. In order to create a closer link between the students and professional development, this system was applied to an Urban Development Plan. Although it would be quite difficult for any single student to cover in detail this technical document, due it would require a huge collective work, the use of ICTs made it possible and allowed interactivity among students. Therefore, a learning community was created and students 
could share their experiences and ideas. In order to achieve this, three design teams were configured. Each one consisted of thirty students grouped in six different thematic clusters and a teacher coordinated them. The goal was to produce three proposals.

In this case, the individual contributions played a significant role in the collective proposal and the teamwork was essential throughout the process. A professional debate could also take place in the classroom based on the contributions of the members of each group. The workshop emphasized a collective learning and created several interactive sessions. Taking into account that excellent results in the production of knowledge could only be obtained if the ICTs were well managed, monitored and evaluated, the exercise was divided in several stages.

Firstly, one group of each team was assigned for one specific thematic territorial area. The goal was to create a more efficient team management providing access to relevant information, reports and tools. Then, each group uploaded all the diagnostic analyses into the e-learning platform. In the second stage, each team had to discover the relationships and conflicts between those different territorial areas. In order to find these links, the students used a range of design tools specifically built for this exercise. At the third stage, the groups had to design an urban reconfiguration proposal. Their results were evaluated using a virtual brainstorming methodology, which allowed us to select the most successful ideas. Finally, the general strategies were selected and the Urban Development Plan became a team result throughout the strategic use of ICTs.

\section{CONCLUSIONS}

To contrast the results obtained using the methodology described above, different meetings between the teachers involved have taken place both at the beginning and at the completion of each semester. These meetings have allowed analysing the information obtained from surveys answered by the students as well as the results of the course from the pass rate data. From them it is possible to present the following conclusions extracted from the first course of application of this experience:

- The pass rate is maintained in the subjects involved, preserving the same range those obtained in previous courses. Besides, compared with the subjects from the Bachelor previous to EHEA a general improvement have been verified in the marks of students: now the subjects is pass by a higher number of students and in addition obtaining better marks.

- Weekly tasks allow a continuous monitoring of the course by the students throughout the semester, increasing approximately $38 \%$ compared to those where they only have to pass a final test. This remarks the continuous assessment procedures allowing in addition better monitoring of student learning and making easier at the same time the comprehension of content. These values have been obtained from the analysis and data about the online activities provided by the virtual campus.

- The common methodology applied to different subjects in the Bachelor in architecture allows to stablish cross relationships between all subjects involved. However, it is necessary to improve and enhance this cross-coordination between subjects from different areas of knowledge making possible the work of the students in projects related to several subjects on the same course during the semester.

In conclusion, it is possible to say that being conscious about the presence of ICTs in all areas of our life, it is essential to design learning tools based on the use of applications that can be used on mobile devices. This will create an environment where students could integrate a new be attractive and friendly teaching experience. This requires to design a new competences - learning framework where the objective is not the simple application of particular theoretical content [8]. On the contrary, this have to be based on a teaching that imply the development of critical thinking directly connected to the analysis of the problem to solve, qualities that have to be applied throughout their professional lives.

\section{ACKNOWLEDGEMENTS}

This project called '“'New frameworks of teaching: ICT applied to problem based learning in technical bachelors" (PIE 15-166) has been funded by the University of Malaga on the Educational Innovation Projects call 2015-2017. 


\section{REFERENCES}

[1] Cimadomo, G., 2014. Teaching History of Architecture. Moving from a knowledge transfer to a multy-participative methodology based on IT tools. Journal of Learning Design, 7(3), pp.79-90.

[2] Vargas-Yáñez, A. \& Ruiz-Jaramillo, J., 2013. La evaluación continua basada en el diseño de actividades formativas electrónicas aplicadas al aprendizaje de las estructuras. In F. J. Alegre Bayo et al., eds. 4th International Conference on Educational Innovation in Technical Careers (INDOTEC 2013). Granada: Godel Ediciones, pp. 245-250.

[3] Justo-Moscardó, E. de, 2013. Diseño y evaluación de un programa para el aprendizaje de Estructuras de Edificación mediante ABP. Seville.

[4] Illanes Maestre, J.L., 1997. Historia y sentido: estudios de teología de la historia 1st ed., Madrid: Ediciones Rialp.

[5] Willis, C. \& Miertschin, S. 2006. Mind maps as active learning tools. Journal of Computing Sciences in Colleges, 21(4), pp. 266-272.

[6] Gunawardena et al. 2009. A theoretical framework for building online communities of practice with social networking tools, Educational Media International, 46(1), pp 3-16.

[7] Cimadomo, C., 2016. Using the Pinterest tool in the course History of Architecture, in the EHEA frame. Digital Education Review, 29(June 2016), pp.181-192.

[8] Santos-Guerra, M.A., 2003. Una flecha en la diana. La evaluación como aprendizaje 1st ed., Madrid: Narcea. 